\title{
Matrix metalloproteinase-10 and microvascular complications of type 1 diabetes: might vitamin $D$ status be relevant?
}

\author{
Barbara J. Boucher
}

Received: 19 January 2014 / Accepted: 22 January 2014 / Published online: 16 February 2014

(C) Springer-Verlag Berlin Heidelberg 2014

Keywords Complications $\cdot$ Diabetes $\cdot$ Matrix

metalloproteinases $\cdot$ MMPs $\cdot$ Microvascular $\cdot$ Vitamin D

\begin{abstract}
Abbreviation
MMP Matrix metalloproteinase
\end{abstract}

To the Editor: Inflammation, with excessive production of matrix metalloproteinase (MMP)-9 in unstable plaque, has a major role in the progression of macrovascular disease, including the development of acute events [1]. In a recent issue of Diabetologia, Toni et al [2] report increased circulating MMP-10 in association with increased microvascular disease risks in type 1 diabetes; this finding is in line with the earlier observations, and, as the authors suggest, provides a potential therapeutic target for reducing microvascular disease risks. Vitamin D repletion is associated with reductions in macrovascular disease risks and, although causation remains unproven, plausible mechanisms exist [3]. Increased circulating MMP-9, inversely correlated with severity of vitamin D insufficiency, was reduced by $\sim 70 \%$ in response to modest improvement in vitamin D repletion in healthy South Asians [4], and circulating MMP-9 increased with reduction in vitamin D status in submariners after an 85 day submerged patrol [5]. Furthermore, MMP-10 formation, increased in peripheral blood mononuclear cells by exposure to Mycobacterium tuberculosis, was inhibited by activated vitamin D [6]. It would, therefore, be useful if Toni and colleagues could examine serum 25-hydroxyvitamin D concentrations in the participants in this study as a potential independent predictor

\section{B. J. Boucher $(\square)$}

Centre for Diabetes and Metabolic Medicine, Blizard Institute, Barts and The London School of Medicine and Dentistry, Queen Mary University of London, 4 Newark Street, London E1 2AT, UK e-mail: bboucher@doctors.org.uk for MMP-10 and microvascular complications, since lower vitamin D status has been found to be associated with increases in the prevalence of both diabetic retinopathy and diabetic nephropathy in a study of patients with type 2 diabetes [7]. If there is such an association, then the potential for reduction in circulating MMP-10 by correction of vitamin D deficiency should be examined early in the search for pharmacological agents to lower MMP-10 production in diabetes, since modest vitamin $\mathrm{D}$ supplementation might prove to be a particularly cost-effective way of reducing the problems of diabetic complications.

Duality of interest The author declares that there is no duality of interest associated with this manuscript.

Contribution statement The author was the sole contributor to this manuscript.

\section{References}

1. Beaudeux JL, Giral P, Bruckert E, Foglietti MJ et al (2004) Matrix metalloproteinases, inflammation and atherosclerosis: therapeutic perspectives. Clin Chem Lab Med 42:121-131

2. Toni M, Hermida J, Goni MJ, Fernandez P et al (2013) Matrix metalloproteinase-10 plays an active role in microvascular complications in type 1 diabetic patients. Diabetologia 56:2743-2752

3. Norman PE, Powell JT (2014) Vitamin D and cardiovascular disease. Circ Res 114:379-393

4. Timms PM, Mannan N, Hitman GA, Noonan K et al (2002) Circulating MMP9, vitamin D and variation in the TIMP-1 response with VDR genotype: mechanisms for inflammatory damage in chronic disorders? Q J Med 95:787-796

5. Baker A, Wood CL, Wood AM, Timms PM et al (2014) Changes in vitamin $\mathrm{D}$ and matrix metalloproteinase-9 in submariners during a submerged patrol. Occup Environ Med 71:104-108

6. Coussens AK, Timms PM, Boucher BJ, Venton AT et al (2009) $1 \propto, 25$ dihydroxyvitamin $\mathrm{D}_{3}$ inhibits matrix metalloproteinases induced by Mycobacterium tuberculosis infection. Immunology 127:539-548

7. Ahmadieh H, Azar ST, Lakkis N, Arabi A (2013) Hypovitaminosis D in patients with type 2 diabetes mellitus: a relation to disease control and complications. ISTN Endocrinol doi:10.1155/2013/641098 